\title{
Simulation of a Maize Ear Picking Device with a Longitudinal Horizontal Roller Based on Hypermesh Modeling
}

\author{
Jianjian Tai, Haitao Li,* Yunyi Guan, Ning Ding, Yuefeng Du, and Enrong Mao
}

\begin{abstract}
As a key component of mechanized maize harvesting, the performance of the ear picking device directly affects the operational level of a maize harvester. Because the short harvest period of maize and the multiple experimental factors that lead to the field and bench tests cannot meet the actual research and developmental needs of manufacturing a maize harvester, this paper uses virtual prototype technology to study the influence of design and the motion parameters of a longitudinal horizontal roller in terms of picking performance. Based on the establishment of the finite element model of the corn and the ear picking device, this paper establishes evaluation indicators respectively, analyzes and evaluates the influence of the picking roller and the ground inclination angle, the picking roller speed, and the forward speed of the harvester on the performance of ear picking. Finally, a virtual orthogonal test analysis was carried out for the two factors of the picking roller speed and the forward speed of the harvester, and the significant influence of the picking roller speed and the forward speed of the harvester on the performance of the picking was compared. The research results of this paper can provide reference for optimizing the design of ear picking mechanism.
\end{abstract}

Keywords: Maize harvester; Maize plant; Picking roller; Finite element; Orthogonal test

Contact information: China Agricultural University, College of Engineering, Beijing 100083 China;

*Corresponding author: h89533@cau.edu.cn

\section{INTRODUCTION}

Ear picking devices are the core of maize ear harvester headers. According to different configuration modes, they can be divided into roller ear picking devices, pulling rollers, or picking plates combined with an ear picking device (Liu et al. 2018). According to their different installation methods, a roller type device can be divided into three types: the longitudinal horizontal roller, the vertical roller, and the horizontal roller. Among them, the longitudinal horizontal roller structure is one of the primary types of maize harvester header used both locally and globally. The longitudinal horizontal roller harvester is a maize harvester header with one or more pairs of ear picking rollers. As the harvester moves, each row of plants, in turn, enters between the two rollers. The mutually rotating picking rollers pull the stalks downward and the maize stalk is pulled off. However, the longitudinal horizontal roller harvesting method can easily cause maize ear gnawing, with up to $30 \%$ of the total ears receiving damage. Moreover, due to the impact of the picking roller, the seeds can easily break and fall off at the root of the maize ear, resulting in a large portion of the harvest being lost, as well as a high proportion of damage (Cui et al. 2019).

Some scientific research institutes and universities, both local and abroad, have performed research on the biomechanical properties of maize and ear picking related injury 
(Martin et al. 1987; Hiregoudar et al. 2011; Cook et al. 2014; Saini et al. 2015; Cheng et al. 2016; Yang et al. 2016; Aguayo et al. 2017; Fu et al. 2019, 2020). Balastreire et al. (1982) accurately measured the critical value of the fracture toughness of maize. Brass and Marley (1973) carried out experiments on the mechanical properties of maize seeds and found that the mechanical properties of different parts of seeds were different, as well as their degrees of impact force. Srivastava et al. (1976) studied the shear properties of maize under an impact load, and the results showed that the shear strength of maize was inversely proportional to its water content and proportional to its impact velocity. According to the compression, shear, and impact tests performed on maize kernels, Zhao et al. (1996) verified that the compressive and shear strength of maize kernels decreased as the water content increased. Zhou (2010) carried out experiments on the impact characteristics of maize ears, i.e., its moisture content, different impact direction, and impact position. Fan et al. (2002) analyzed the factors affecting the rate of kernel breakage and the picking process loss percentage and obtained the experimental combination with the smallest breakage rate. Zhang et al. (2007) performed an experimental study on the shear fracture values of maize kernels and analyzed the shear characteristics of maize kernels under different forces and moisture contents. By combining theoretical analysis with bench test, Geng et al. (2016) analyzed the damage to corn in the process of ear picking, such as the gap between the picking rollers, ear diameter and ear length.

All of these studies obtained the mechanical properties of corn grains, the combination of optimum parameters, and the main factors influencing the damage resulting from ear picking by using experimental methods, but field experiments or test bench experiments could not meet the current research needs of corn ear picking mechanism. Due to the strong seasonality of maize harvests and their short harvest period, the amount of data is insufficient. If comprehensive data are needed, the time cycle is long. At the same time, due to the variety of maize species, climate differences, water contents, difference in suitable harvest periods, etc., the results of field tests or bench tests cannot fully reflect the working effect of the different varieties and water contents of maize harvest processes in China. Based on the above reasons and combined with the development status of virtual prototype technology, virtual prototype technology was proposed to analyze the corn ear picking process, and the motion parameters and mechanical parameters of the corn ear during the process were obtained through simulation. The corresponding relationship between these parameters and the performance of corn picking mechanism was used to evaluate the performance of corn picking mechanism in order to provide reference for the parameter optimization of a corn picking device.

\section{EXPERIMENTAL}

\section{Solid Modeling of the Maize Plant and Picking Roller}

Physical properties and modeling of maize

According to the requirements of the GB/T 21961 (2008), the test indexes and methods were selected. The maize variety Zhengdan 958 was selected for this test. In September 2019, the plants in the maize planting experimental field of the China Agricultural University were determined to be in the full ripe stage. In the experimental area, four representative lines were selected for determination, with 10 plants in each line, and a total of 40 data groups. The measured indexes included the following: the plant natural height, ear height, ear diameter, ear length, length of the ear stalk, diameter of the 
ear stalk, diameter of the root stem, and stem diameter at the ear. The measured parameters of the maize samples were sorted and counted, and the size distribution was obtained, as shown in Fig. 1.

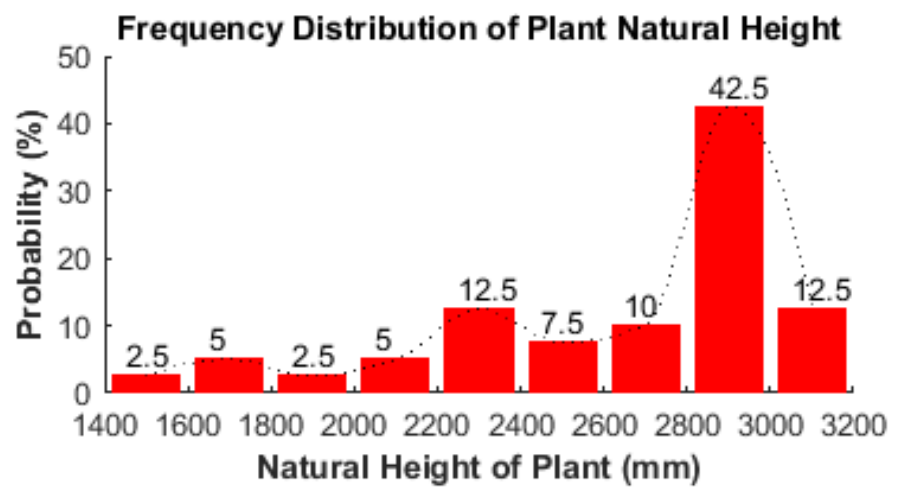

a

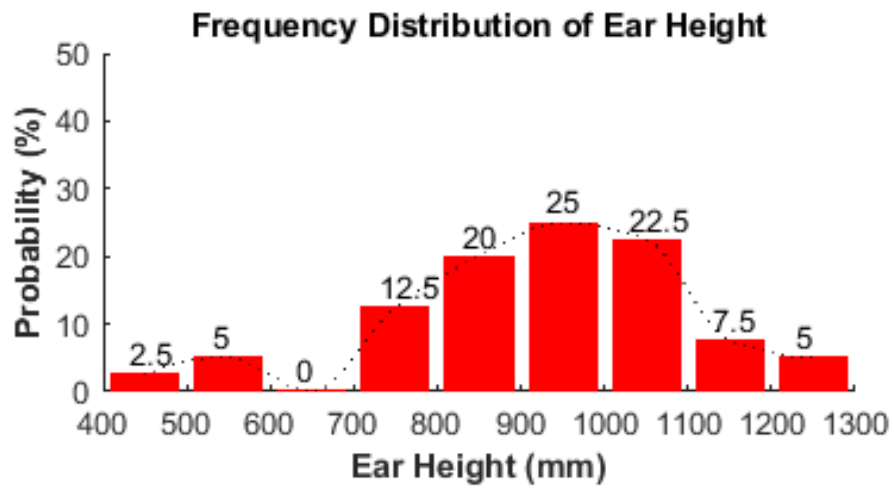

b

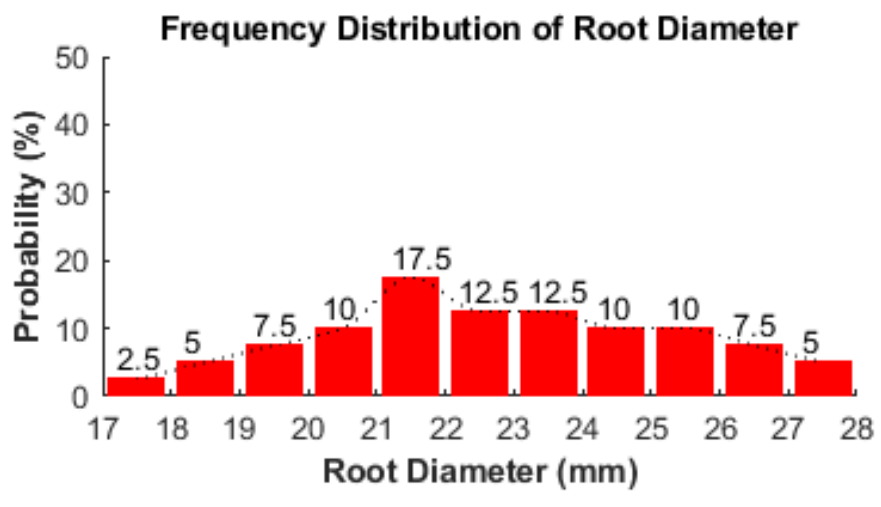

C

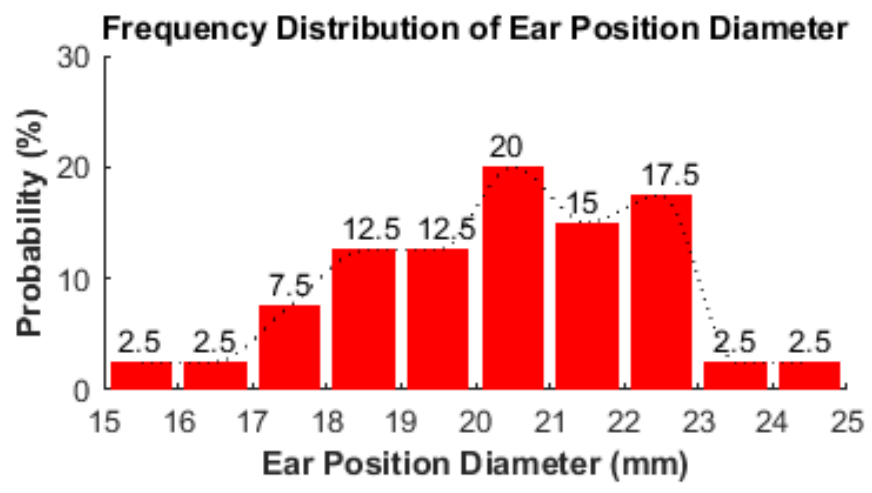

d 


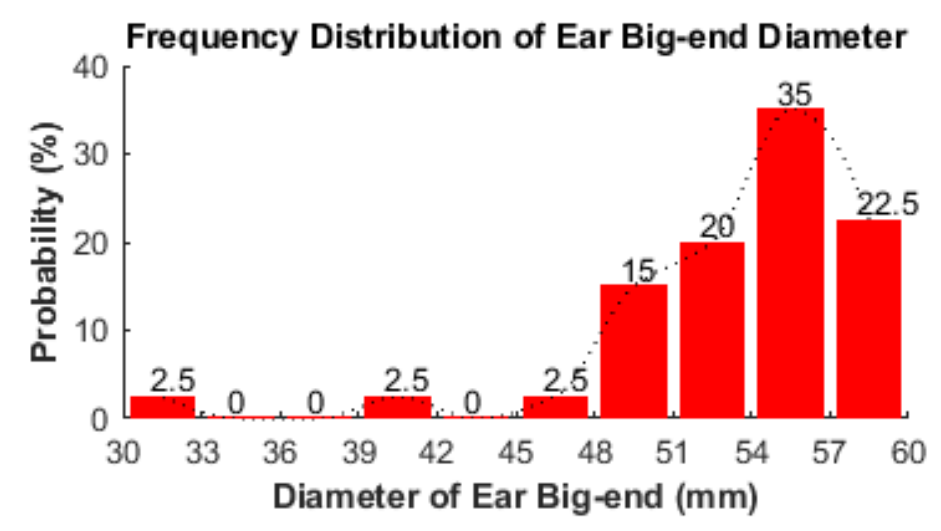

e
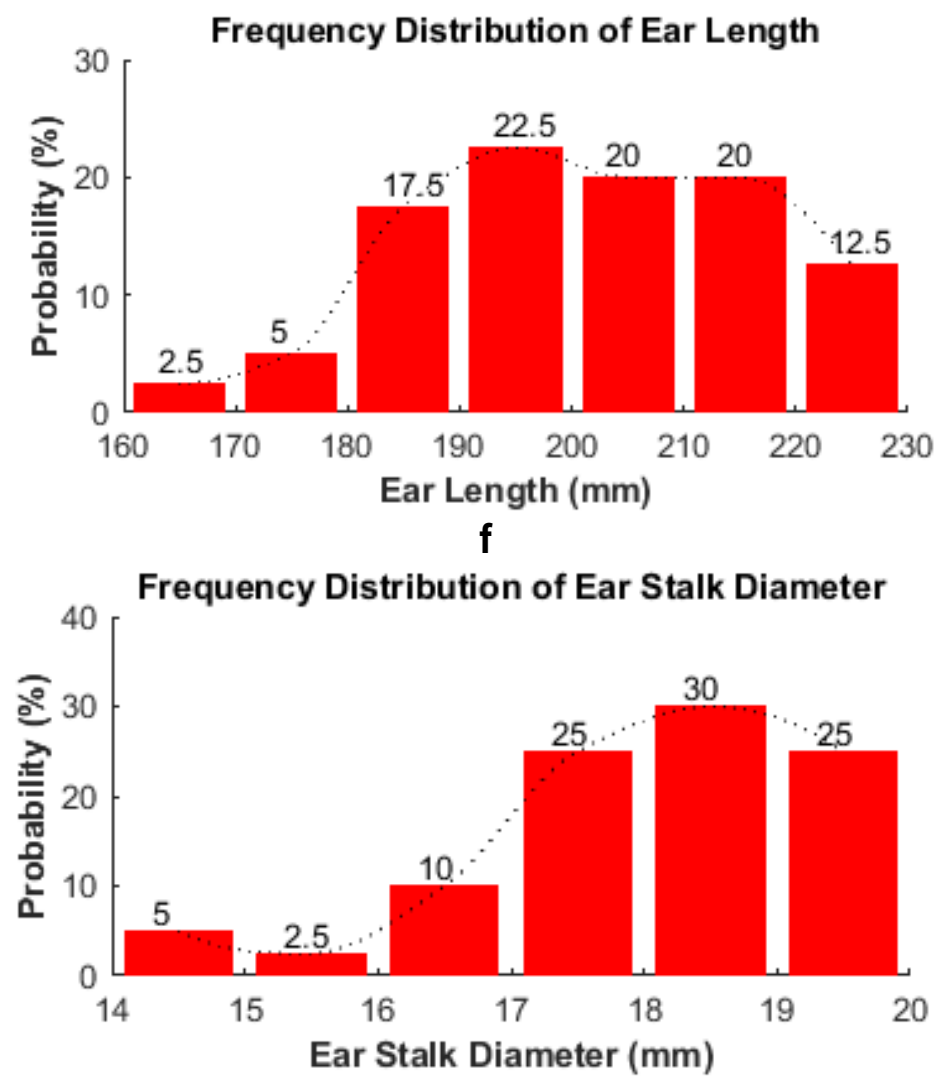

g

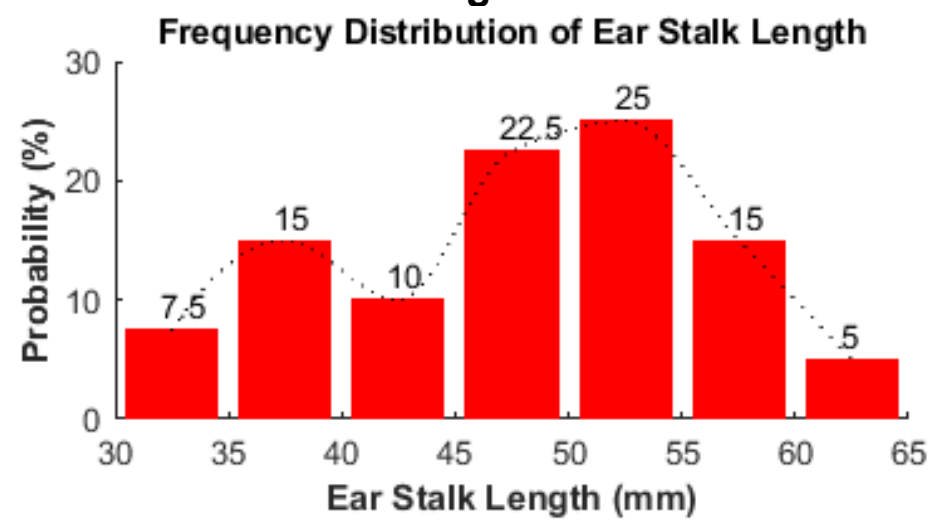

h

Fig. 1. Probability statistics of the maize plant size distribution measured in the field 
According to the distribution of various parameters of corn plants, based on the mathematical expectation value of each parameter and combined with the distribution of its frequency, reasonable modeling parameters were selected to establish a threedimensional solid model of corn plants. The selected parameters are shown in Table 1.

Table 1. Selection Data of Maize Plant Modeling

\begin{tabular}{|c|c|c|c|c|c|c|c|c|}
\hline Item & $\begin{array}{l}\text { Plant } \\
\text { Height } \\
h(\mathrm{~mm})\end{array}$ & $\begin{array}{c}\text { Ear } \\
\text { Height } \\
\text { of } \\
\text { Maize } \\
h_{0} \\
(\mathrm{~mm})\end{array}$ & $\begin{array}{l}\text { Root } \\
\text { Diameter } \\
\text { of the } \\
\text { Plant } d_{0} \\
(\mathrm{~mm})\end{array}$ & $\begin{array}{l}\text { Diameter } \\
\text { of Ear } \\
\text { Position } \\
d \quad(\mathrm{~mm})\end{array}$ & $\begin{array}{l}\text { Diameter } \\
\text { of Ear } \\
\text { Big-end } \\
d_{g}(\mathrm{~mm})\end{array}$ & $\begin{array}{l}\text { Ear } \\
\text { Length } \\
I(\mathrm{~mm})\end{array}$ & $\begin{array}{c}\text { Ear Stalk } \\
\text { Diameter } \\
d_{1}(\mathrm{~mm})\end{array}$ & $\begin{array}{c}\text { Ear } \\
\text { Stalk } \\
\text { Length } \\
10 \\
(\mathrm{~mm})\end{array}$ \\
\hline $\begin{array}{c}\text { Numerical } \\
\text { value }\end{array}$ & 2850 & 950 & 22 & 20 & 55 & 195 & 18 & 50 \\
\hline
\end{tabular}
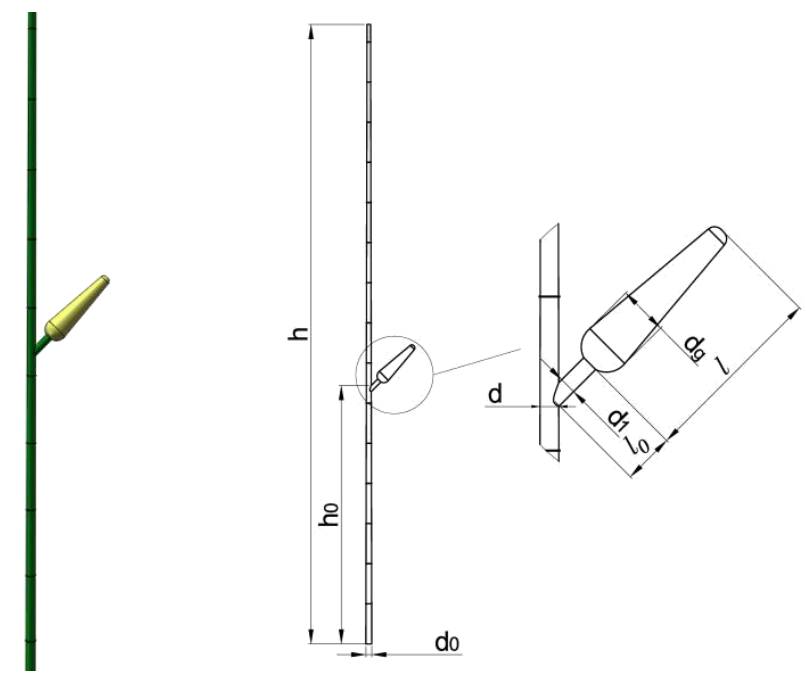

Fig. 2. Solid model of the maize plant

Because the protective effect of the maize bracts on the maize ears was not considered in the simulation process, the maize ear bracts will not appear in the simulation. In addition, since the purpose of the simulation was to obtain the force applied to the bottom of the maize ear, the force applied to each maize kernel could be approximated. Therefore, the maize ears were no longer refined, and the whole maize ear was analyzed as a whole. The simplified plant is composed of a stalk, stalk node, ear stem, and ear. According to the data in Table 1, the solid maize plant model was established using Siemens NX drawing software (version 10.0, Siemens PLM Software, Plano, Texas), as shown in Fig. 2.

Design and solid modeling of the longitudinal horizontal roller ear picking device

As shown in Fig. 3, the ear picking roller was designed according to the two following conditions: the ear picking roller can grasp the stalk and the ear picking roller cannot grasp the ear.

The diameter design of the picking roller should meet the following requirements, as stated by Eq. 1, 


$$
\frac{d-h}{1-\frac{1}{\sqrt{\mu_{j}^{2}+1}}} \leq D \leq \frac{d_{g}-h}{1-\frac{1}{\sqrt{\mu_{g}^{2}+1}}}
$$

where $h$ is the horizontal clearance between the two picking rollers (mm), $d$ is the maize stalk diameter at the ear position $(\mathrm{mm}), d_{g}$ is the big-end ear $(\mathrm{mm}), \mu_{j}$ is the equivalent friction coefficient of the picking roller to stalk, $\mu_{g}$ is the equivalent friction coefficient of the picking roller to ear, and $D$ is the diameter of the picking roller ( $\mathrm{mm}$ ).

The horizontal clearance between the two picking rollers should meet the following requirements, as shown in Eq. 2,

$$
h=0.3 d \sim 0.5 d
$$

where $h$ is the horizontal clearance between the two picking rollers, $d$ is the maize stalk diameter at the ear position , $d_{\mathrm{g}}$ is the big-end ear $(\mathrm{mm}), D$ is the diameter of the picking roller, $\beta$ is the horizontal inclination angle of the pick roll, and $\mathrm{L}$ is the length of the pick roll.
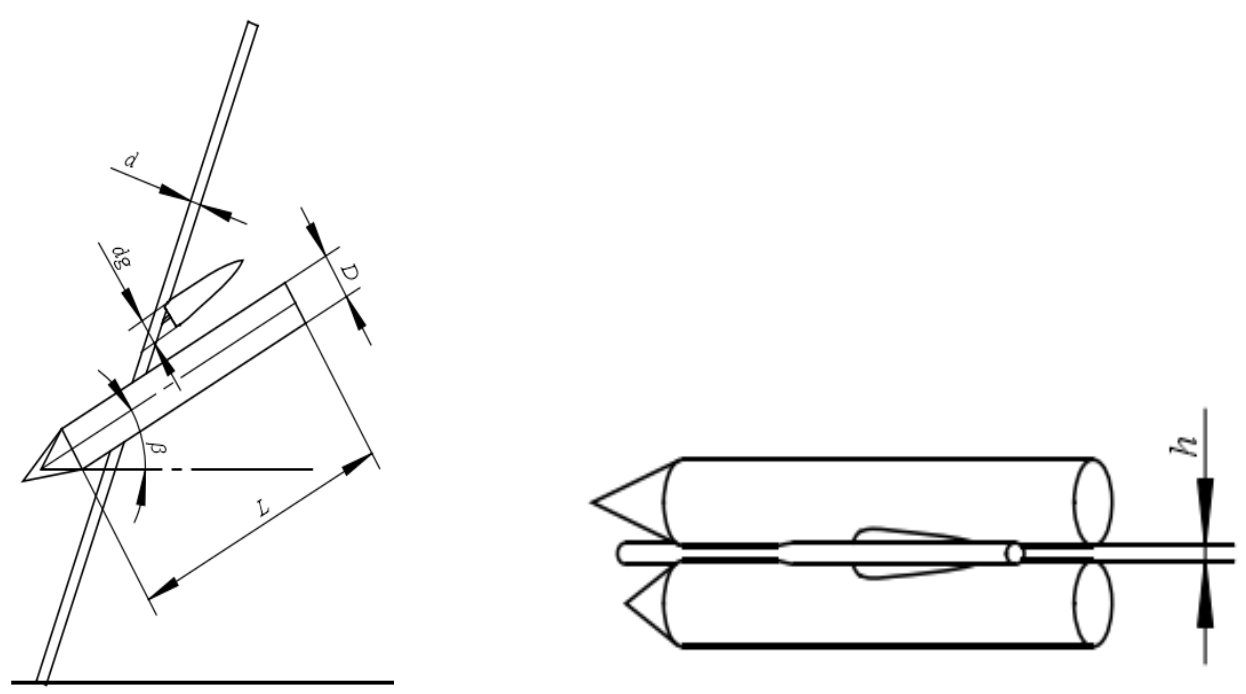

Fig. 3. Schematic diagram of the harvesting principle and structure of the picking roller

The minimum working length of the picking section should ensure that the highest and lowest ears at the ear position can be picked, as shown in Fig. 4 . The $L_{\text {min }}$ can be calculated according to Eq. 3,

$$
L_{\min }=L_{\mathrm{g}} / \sin \beta
$$

where $\beta$ is the horizontal dip angle of the picking roller $\left(^{\circ}\right)$, and $L_{g}$ is the height difference between the highest and lowest ears ( $\mathrm{mm})$.

According to the selected data used for the maize plant modeling, when combined with Eqs. 1, 2, and 3, the dimensions of the picking roller were determined as follows: the diameter of the picking roller was $\mathrm{D}=70 \mathrm{~mm}$; the horizontal clearance of the two picking rollers was $h=8 \mathrm{~mm}$; and the length of the ear picking roller was $L=700 \mathrm{~mm}$. 


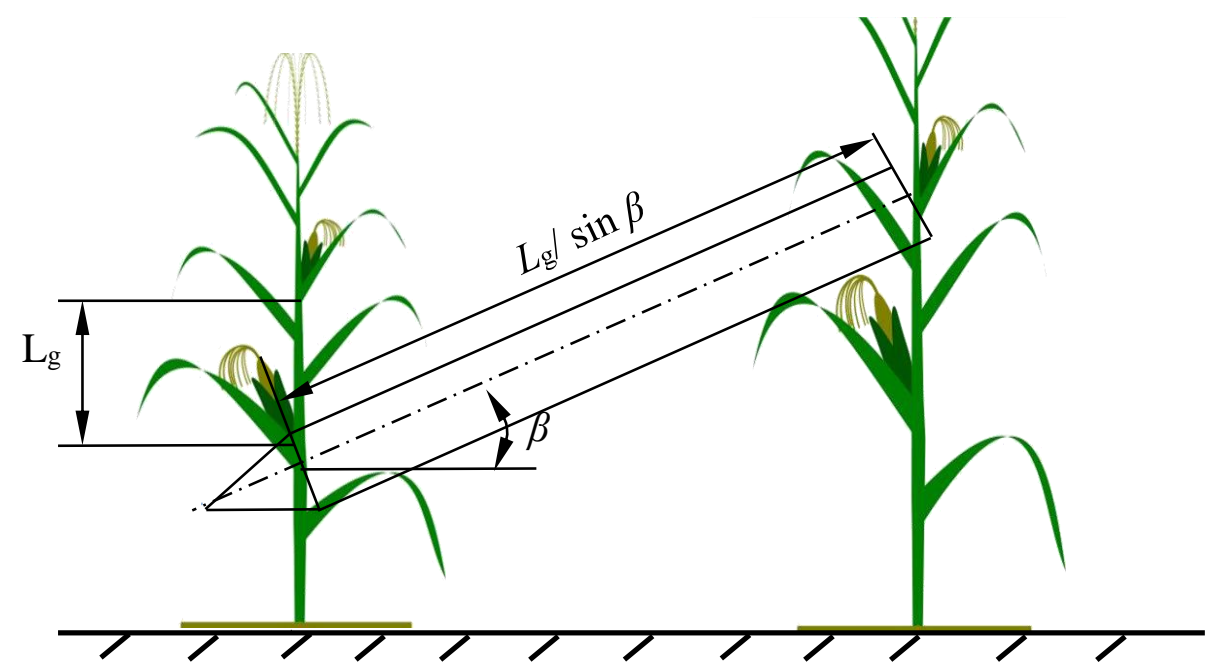

Fig. 4. Working length of the horizontal picking roller

For the actual production process, the roller ear picking mechanism is primarily composed of three parts: the ear picking roller, the reel chain, and the conveying device. Considering that the finite element model needs to reflect the real situation as much as possible, while the virtual prototype simulation test time cannot be too long, the picking mechanism model was simplified as a pair of picking rollers with spiral ribs. According to the above design data, the model of the picking roller was established using NX drawing software. The model is shown in Fig. 5.

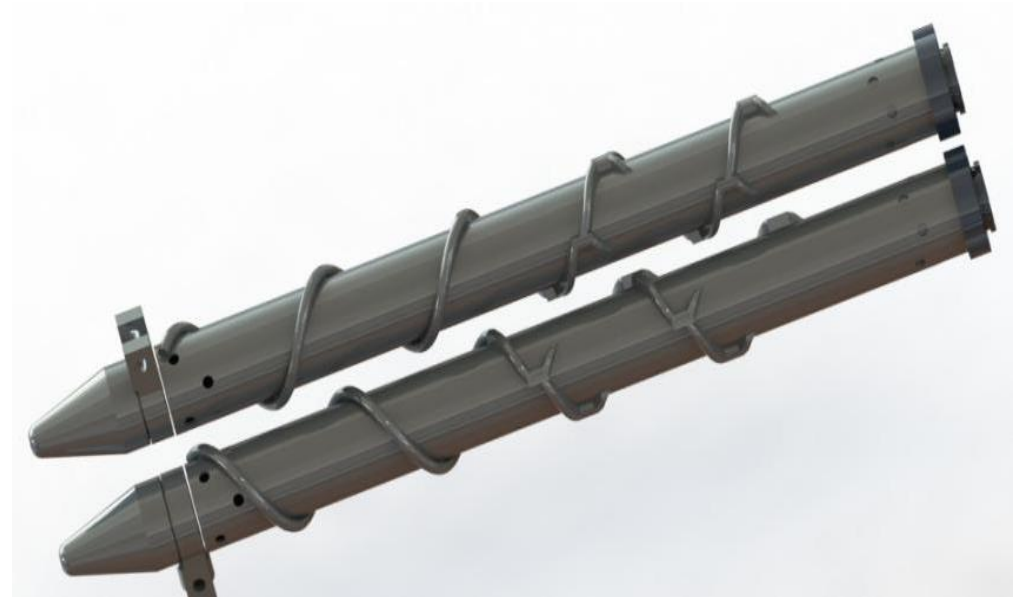

Fig. 5. Solid model of the ear picking device

\section{Establishment of the Finite Element Model of the Maize Plant and Ear Picking Mechanism}

The 3D solid model established in NX was imported into Hyper-Mesh through the interface between Siemens NX and Hypermesh (version 12.0, Altair, Troy, MI), and the finite element model of the maize plant and ear picking mechanism was established. In the simulation analysis, a hexahedron was selected to divide the regular structural parts, and a tetrahedron was selected to divide the irregular structural parts.

Rubber materials were used for the maize stalk, maize stalk node, and maize ear, which belonged to the hyper-elastic model. Therefore, MAT_Johnson-cook was used as 
the material model for the maize stalk, maize stalk node, and maize ear. At the same time, since there is no deformation of the picking roller and plate during the actual picking process, and the material itself is a rigid body, MAT_SOLID was selected as the material model of the picking roller in the simulation analysis. Under the known conditions of the material model, i.e., the density, elastic modulus, and Poisson ratio, the related parameters calculated from the above parameters were defined. The basic parameters of the material properties of each component of the simulation model are shown in Table 2.

Table 2. Basic Parameters of the Material Properties of the Maize Plant and Picking Roller

\begin{tabular}{|c|c|c|c|}
\hline Item & Density $\left(\mathrm{g} / \mathrm{cm}^{3}\right)$ & $\begin{array}{c}\text { Elastic Modulus } \\
(\mathrm{GPa})\end{array}$ & Poisson Ratio \\
\hline Maize plant & 0.9 & 0.06 & 0.33 \\
\hline Picking roller & 7.8 & 120 & 0.3 \\
\hline
\end{tabular}

In this paper, the lines were used to set the unit side length. The unit side length of the finite element model of the ear picking roller, maize stalk, maize ear, and maize ear stalk were set as $0.05 \mathrm{~m}$, and the unit side length of the finite element model of the maize stalk node was $0.04 \mathrm{~m}$. According to the topological structure of the geometric solid model in the sweeping direction, a sweeping mesh was selected. The finite element model of the maize plant and the picking roller is shown in Fig. 6.

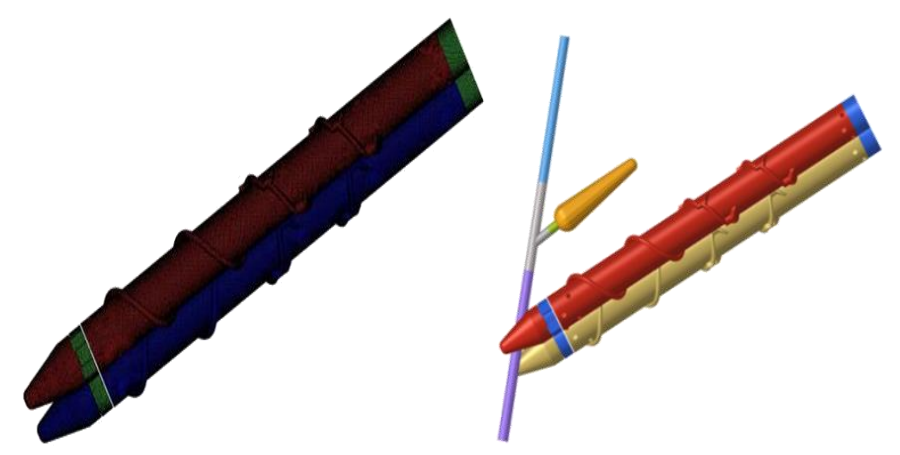

Fig. 6. Finite element model of the maize plant and ear picking roller as well as their interaction force

According to the material characteristics and related theories of the picking roller and maize plant, the contact parameter data used in the simulation model was obtained. The specific parameters are shown in Table 3.

Table 3. Contact Parameters

\begin{tabular}{|c|c|c|c|c|c|}
\hline Item & $\begin{array}{c}\text { Static Friction } \\
\text { Coefficient }\left(F_{S}\right)\end{array}$ & $\begin{array}{c}\text { Dynamic } \\
\text { Friction } \\
\text { Coefficient } \\
\left(F_{D}\right)\end{array}$ & $\begin{array}{c}\text { Exponential } \\
\text { Attenuation } \\
\text { Coefficient } \\
\left(D_{C}\right)\end{array}$ & $\begin{array}{c}\text { Viscous } \\
\text { Friction } \\
\text { Coefficient } \\
\left(V_{F C}\right)\end{array}$ & $\begin{array}{c}\text { Viscous } \\
\text { Contact } \\
\text { Damping } \\
\left(V_{D C}\right)\end{array}$ \\
\hline $\begin{array}{c}\text { Maize stalk and } \\
\text { picking roller }\end{array}$ & 0.89 & 0.728 & 0.001 & 0.0 & 30 \\
\hline $\begin{array}{c}\text { Maize ear and } \\
\text { picking roller }\end{array}$ & 0.75 & 0.645 & 0.001 & 0.0 & 30 \\
\hline
\end{tabular}




\section{Simulation Analysis Based on the Finite Element Model}

The forward speed of the harvester was set as $1.5 \mathrm{~m} / \mathrm{s}$, and the rotational speed was $1000 \mathrm{rpm}$. Before entering the picking device, the maize plant will tilt forward due to the feeding action of the reel chain. For this picking device, the maize plant is inclined towards the direction of picking device at a $10^{\circ}$ angle. The dip angle between the picking roller and the ground was selected as simulation variable, and the tested dip angles ranged from $28^{\circ}$ to $36^{\circ}$ with a total of 9 groups of tests. The stress on the bottom of the ear caused by the dip angle between the picking device and the horizontal ground was studied. Through virtual simulation, the contact forces of the 18 selected points under 9 working conditions were obtained, as shown in Table 4. According to statistics, the maximum and absolute values of forces on the bottom of corn ear at different dip angles are shown in Table 5.

Table 4. Force Statistics of 18 Units at the Moment of Ear Picking Unit: N

\begin{tabular}{|c|c|c|c|c|c|c|c|c|c|}
\hline $\begin{array}{l}\text { Unit No } \\
\text { Dip Angle }\left(^{\circ}\right)\end{array}$ & 28 & 29 & 30 & 31 & 32 & 33 & 34 & 35 & 36 \\
\hline 31187 & 1704 & 1222 & 4 & 3 & 116 & 1553 & 1366 & 4533 & 4763 \\
\hline 30761 & 41 & 1377 & 1882 & 589 & 249 & 386 & 530 & 736 & 2 \\
\hline 30035 & 3045 & 1030 & 193 & 183 & 1647 & 5 & 3398 & 72 & 7 \\
\hline 29909 & 5 & 322 & 19 & 3 & 7 & 3 & 4 & 72 & 385 \\
\hline 29226 & 2 & 202 & 144 & 5 & 37 & 488 & 610 & 2 & 661 \\
\hline 28800 & 605 & 251 & 29 & 5 & 3 & 374 & 344 & 187 & 4102 \\
\hline 30336 & 4206 & 738 & 609 & 98 & 6 & 4 & 255 & 602 & 3 \\
\hline 30762 & 341 & 393 & 41 & 703 & 1067 & 17 & 417 & 1233 & 4 \\
\hline 31188 & 1132 & 2899 & 8 & 3 & 221 & 738 & 546 & 2025 & 176 \\
\hline 28801 & 631 & 239 & 373 & 125 & 1 & 541 & 1297 & 664 & 4942 \\
\hline 29227 & 6 & 37 & 319 & 119 & 1401 & 198 & 1114 & 2 & 826 \\
\hline 29908 & 6 & 379 & 19 & 3 & 154 & 1 & 219 & 80 & 454 \\
\hline 30334 & 785 & 899 & 83 & 8 & 353 & 274 & 1003 & 3192 & 80 \\
\hline 30760 & 18 & 1292 & 1778 & 8 & 42 & 189 & 172 & 1047 & 0 \\
\hline 31186 & 277 & 781 & 3 & 4 & 14 & 1713 & 826 & 1113 & 2417 \\
\hline 31612 & 1805 & 1671 & 3 & 44 & 125 & 253 & 3134 & 1300 & 2014 \\
\hline 29910 & 2 & 349 & 2 & 2 & 1 & 19 & 2 & 3 & 724 \\
\hline 29225 & 148 & 502 & 2 & 1 & 2 & 253 & 188 & 42 & 415 \\
\hline & & & & & & & & & \\
\hline
\end{tabular}


Table 5. Statistics of the Maximum Force and Absolute Value of Different Inclinations

\begin{tabular}{|c|c|c|c|c|c|c|c|c|c|}
\hline Project & 28 & 29 & 30 & 31 & 32 & 33 & 34 & 35 & 36 \\
\hline Maximum force (N) & 4206 & 2899 & 1882 & 589 & 1647 & 1713 & 3398 & 4533 & 4942 \\
\hline $\begin{array}{c}\text { Absolute value sum } \\
\text { of forces (N) }\end{array}$ & 14759 & 14583 & 5511 & 1906 & 5446 & 7009 & 15423 & 16905 & 21975 \\
\hline
\end{tabular}

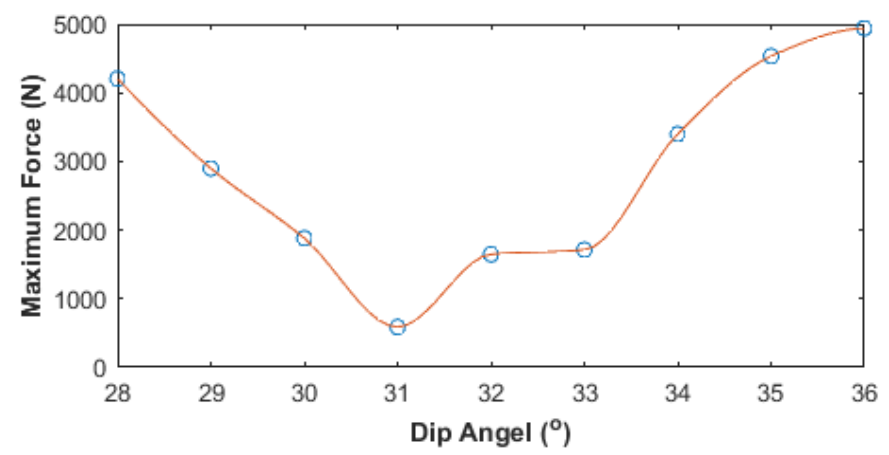

Fig. 7. The relation between the maximum force on selected element and dip angle

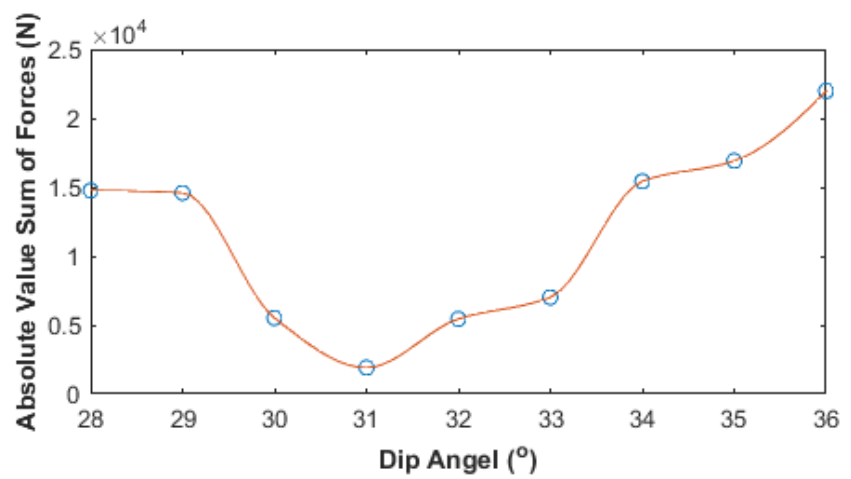

Fig. 8. The relation between absolute force value and dip angle of selected element

It can be seen in Table 5 that when the dip angle between the picking roller and the ground is $28^{\circ}$ to $31^{\circ}$, as the dip angle increases, the total contact force on all units as well as the maximum force on the unit are predicted to gradually decrease. When the dip angle between the picking roller and the ground is $31^{\circ}$, the total contact force of all the units is at its minimum, and the maximum force of the unit is also at its minimum. When the angle between the picking roller and the ground is $31^{\circ}$ to $36^{\circ}$, the total contact force on all units and the maximum force on the unit gradually increase. As the dip angle is changed, the trends of the total force and maximum force of the selected elements are shown in Figs. 8 and 9. The above simulation shows that, when the inclination angle is small, the contact time between the picking roller and the ear is relatively long, which leads to more stress points at the bottom of the ear of corn and longer time. When the angle of inclination is too large, the impact force of the picking roller on the ears will increase, causing gnawing injuries to the bottom of the ears and part of the grains falling to the field ground, resulting in harvest loss.

It can be seen in Tables 4 and 5 that the contact force of the picking roller with 
spiral ribs is relatively concentrated, which makes the force on the ear uneven and yields a large force difference at each position. This is also the primary reason for ear gnawing and kernel breakage. Therefore, measures such as increasing the diameter of the picking roller, reducing the height of the spiral rib, improving the smoothness of the picking roller, and spraying plastic on the surface of picking roller can effectively reduce the maize kernel breakage rate and ear damage rate.

\section{Effect of the Rotational Speed on the Ear Harvesting Force and Harvesting Time}

The forward speed of the harvester was set as $1.8 \mathrm{~m} / \mathrm{s}$, and the angle between the picking roller and the ground was $30^{\circ}$. Before entering the picking device, the posture will tilt forward due to the feeding action of the reel chain. For this picking device, the maize plant is inclined towards the direction of picking device at a $10^{\circ}$ angle. For this test, rotational speed was set to $800 \mathrm{rpm}, 900 \mathrm{rpm}, 1000 \mathrm{rpm}, 1100 \mathrm{rpm}$, and $1200 \mathrm{rpm}$ as the simulation variable. The effect of the rotational speed on the stress at the bottom of ear and picking time were studied. Through virtual simulation, the curve of the maximum contact force and picking time of the ear in the picking mechanism for five working conditions were obtained, as shown in Fig. 9.

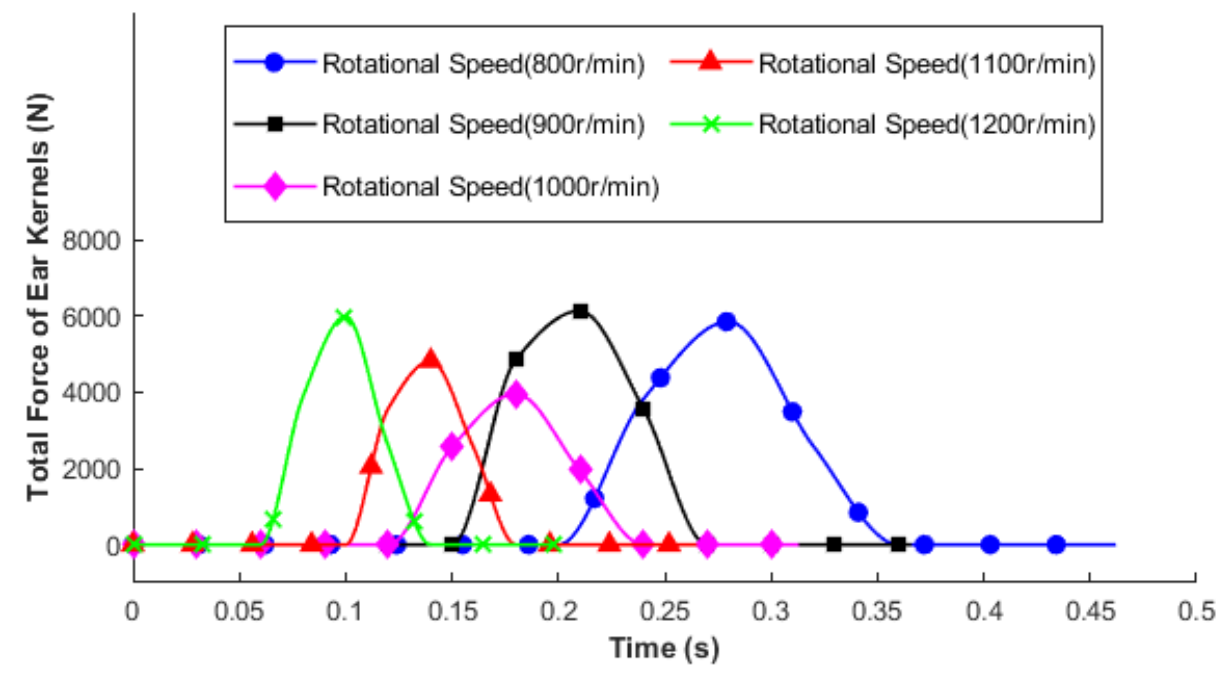

Fig. 9. The ear contact force and the picking time at different rotational speed

It can be seen in Fig. 9 that as the rotational speed increases, the sum of the instantaneous maximum contact force between the bottom of the ear and the picking roller gradually increases, and the time gradually decreases. The total force of the 18 selected points fluctuated from $3956 \mathrm{~N}$ to $6128 \mathrm{~N}$; the average stress of each point increased by 220 $\mathrm{N}$ to $340 \mathrm{~N}$, and the overall picking time gradually decreased by $0.198 \mathrm{~s}$ to $0.462 \mathrm{~s}$. These results were caused by the increase of the speed, which can be explained according to the momentum theorem. The increment of momentum of an object is equal to the impulse of the combined external force. The impact force is directly proportional to the impact velocity and inversely proportional to the impact time. When the rotational speed increases, the vertical speed of the maize stalk gradually increases, and the required picking time decreases. Thus, the contact force between the ear and the picking roller will gradually increase.

Combined with the actual process of picking, it can be seen that increasing the 
rotational speed can improve the efficiency of the ear picking process. At the same time, it will also cause greater damage to the kernels, especially when the moisture content of the kernels is relatively high. According to the mechanical properties of a kernel, the maximum extrusion and impact force that the kernel can bear is approximately $300 \mathrm{~N}$ to $500 \mathrm{~N}$. When the rotational speed is too high, the protection provided by the bracts on the kernel is limited, which will inevitably cause cracks in the kernel or for it drop directly.

\section{Effect of the Forward Speed of the Harvester on the Ear Harvesting Force}

The rotational speed was set to $1000 \mathrm{rpm}$, and the dip angle between the picking roller and ground was $30^{\circ}$. The plant tilted at a $10^{\circ}$ angle to the picking device before entering the picking device. For this test, the speed of the picking roller was set to $0.9 \mathrm{~m} / \mathrm{s}$, $1.2 \mathrm{~m} / \mathrm{s}, 1.5 \mathrm{~m} / \mathrm{s}, 1.8 \mathrm{~m} / \mathrm{s}$ and $2.1 \mathrm{~m} / \mathrm{s}$ as the simulation variable. The effect of the rotational speed on the stress at the bottom of the ear and the picking time were studied.

The curve of the force situation and picking time of the ear in the picking mechanism for five working conditions were obtained, as shown in Fig. 10.

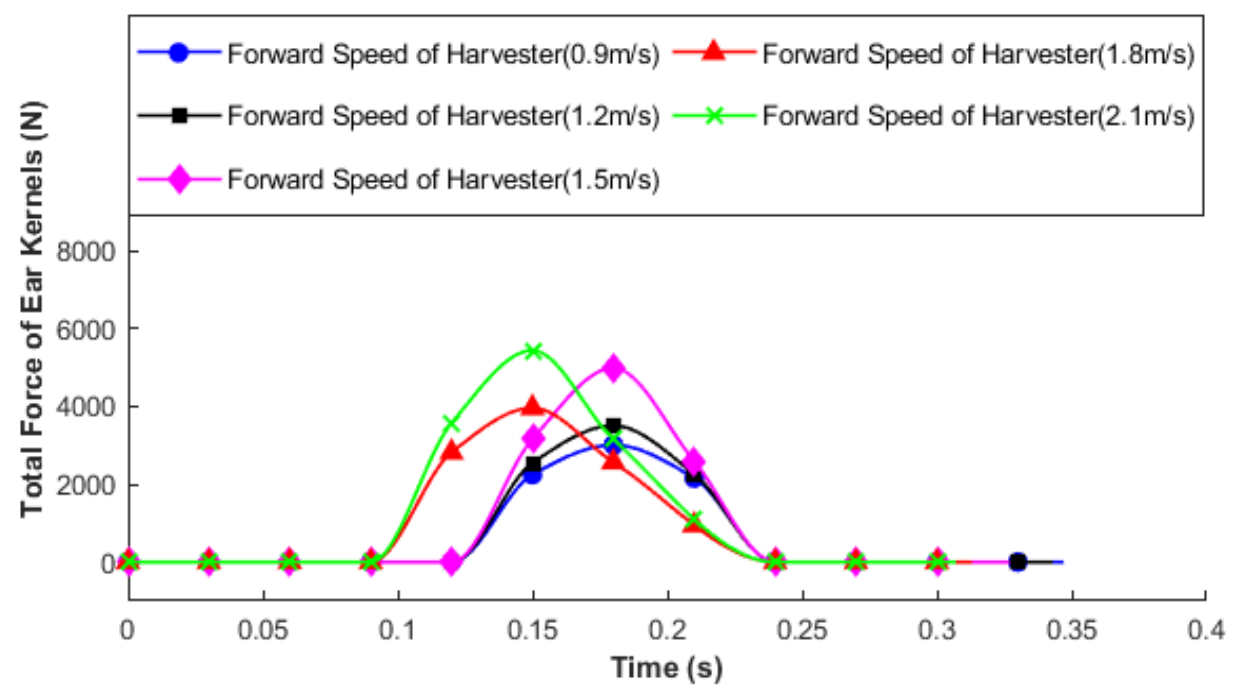

Fig. 10. The ear contact force and the picking time at different forward speeds of the harvester

It can be seen in Fig. 10 that as the forward speed increases, the sum of the instantaneous maximum contact force between the ear bottom and the picking roller fluctuates between $3006 \mathrm{~N}$ and $5433 \mathrm{~N}$, and the average stress at each point ranges from $167 \mathrm{~N}$ to $302 \mathrm{~N}$, but the overall trend gradually increases. Meanwhile, as the forward speed is increased, the picking time is decreased by $0.347 \mathrm{~s}$ to $0.307 \mathrm{~s}$. The reason for this is that the inertia in the forward direction increases and the impact force of the ear increases with an increase of the working speed, which leads to an increase of the instantaneous contact force between the ear and the picking roller. Thus, the picking time was reduced.

\section{Virtual Orthogonal Experiment of the Picking Process}

Taking the rotational speed and the forward speed of the harvester as the experimental factors, and taking the contact force between the ear and the picking roller as well as the picking time as the response values, the orthogonal experiment was conducted at two factor levels. The factors and coding levels of the virtual orthogonal test are shown in Table 6. 
Table 6. Factor Levels of the Virtual Orthogonal Test

\begin{tabular}{|c|c|c|}
\hline Coding Level & $\begin{array}{c}\text { Factor A: Speed of the Picking } \\
\text { Roller }(\mathrm{r} / \mathrm{min})\end{array}$ & $\begin{array}{c}\text { Factor B: Forward Speed of the } \\
\text { Harvester }(\mathrm{m} / \mathrm{s})\end{array}$ \\
\hline-2 & 800 & 0.9 \\
\hline-1 & 900 & 1.2 \\
\hline 0 & 1000 & 1.5 \\
\hline 1 & 1100 & 1.8 \\
\hline 2 & 1200 & 2.1 \\
\hline
\end{tabular}

Through virtual experiment simulation, the results are shown in Table 7 . The orthogonal experimental design model combination test was carried out for the rotational speed and the harvester operation speed at the coding levels shown in Table 7. The results showed that the collision force between the ear and the picking roller ranged from $2821 \mathrm{~N}$ to $7440 \mathrm{~N}$, with an average force of $156.72 \mathrm{~N}$ to $413.00 \mathrm{~N}$, while the picking time ranged from $0.148 \mathrm{~s}$ to $0.572 \mathrm{~s}$.

Table 7. Results of the Virtual Orthogonal Test

\begin{tabular}{|c|c|c|c|c|}
\hline Test No. & $\begin{array}{c}\text { Factor } \\
\text { a:Rotational } \\
\text { speed (r/min) }\end{array}$ & $\begin{array}{c}\text { Factor b: Forward } \\
\text { Speed of the } \\
\text { Harvester (m/s) }\end{array}$ & $\begin{array}{l}\text { Contact Force } \\
\text { Between the Ear } \\
\text { and the Picking } \\
\text { Roller } Y_{1}(\mathrm{~N})\end{array}$ & $\begin{array}{c}\text { Picking Time } Y_{2} \\
\text { (s) }\end{array}$ \\
\hline 1 & -2 & -2 & 6202 & 0.572 \\
\hline 2 & -1 & -2 & 6180 & 0.492 \\
\hline 3 & 0 & -2 & 3006 & 0.463 \\
\hline 4 & 1 & -2 & 2821 & 0.462 \\
\hline 5 & 2 & -2 & 5675 & 0.461 \\
\hline 6 & -2 & -1 & 6538 & 0.416 \\
\hline 7 & -1 & -1 & 6157 & 0.413 \\
\hline 8 & 0 & -1 & 3502 & 0.412 \\
\hline 9 & 1 & -1 & 5427 & 0.366 \\
\hline 10 & 2 & -1 & 6523 & 0.350 \\
\hline 11 & -2 & 0 & 6127 & 0.347 \\
\hline 12 & -1 & 0 & 5964 & 0.343 \\
\hline 13 & 0 & 0 & 4982 & 0.327 \\
\hline 14 & 1 & 0 & 6329 & 0.313 \\
\hline 15 & 2 & 0 & 7440 & 0.307 \\
\hline 16 & -2 & 1 & 5848 & 0.287 \\
\hline 17 & -1 & 1 & 6127 & 0.277 \\
\hline 18 & 0 & 1 & 3956 & 0.274 \\
\hline 19 & 1 & 1 & 4818 & 0.265 \\
\hline 20 & 2 & 1 & 5988 & 0.232 \\
\hline 21 & -2 & 2 & 6304 & 0.219 \\
\hline 22 & -1 & 2 & 6157 & 0.202 \\
\hline 23 & 0 & 2 & 5433 & 0.200 \\
\hline 24 & 1 & 2 & 5202 & 0.198 \\
\hline 25 & 2 & 2 & 5608 & 0.148 \\
\hline
\end{tabular}


Using MATLAB software (2017bversion, MathWorks, Natick, MA), the response surface analysis experiments were performed with the rotational speed (a) and the working speed $(b)$ of the harvester as the experimental factors, and the contact force $\left(Y_{1}\right)$ and the picking time $\left(Y_{2}\right)$ of the ear and picking roller as the response values. The regression equation of the ear contact force $\left(Y_{1}\right)$ expressed by the coding value is shown in Eq. 4,

$$
\begin{aligned}
& Y_{1}=-78814.697+370.288 a-46771.492 b+124.428 a b- \\
& 0.509 a^{2}-8972.539 b^{2}-0.04 a^{2} b-14.057 a b^{2}+4716.049 b^{3}
\end{aligned}
$$

where $a$ is the rotational speed (rpm), and $b$ is the speed of the harvester $(\mathrm{m} / \mathrm{s})$. According to the regression equation shown in Eq. 4, the response surface diagram of the rotational speed (a) and the forward speed (b) of the harvester with the contact force is shown in Fig. 11.

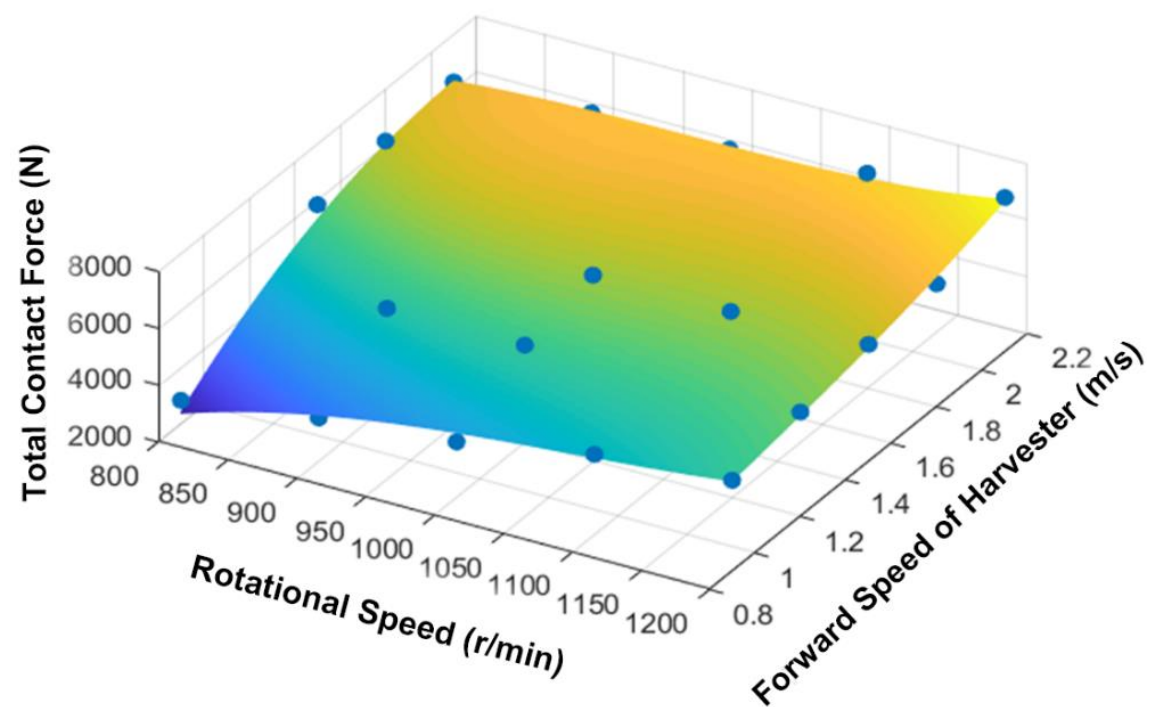

Fig. 11. Effect of the rotational speed and the working speed of the harvester on the contact force

When the rotational speed is fixed at a certain level, the contact force tends to swing with the increase of the machine speed, i.e., the contact force gradually increases as the speed increases, and there is a minimum value in the middle. The overall change in value is not obvious. From the partial regression analysis, it can be concluded that the impact of the rotational speed on the contact force is greater than the effect of the forward working speed of the harvester.

The regression equation of picking time $\left(Y_{2}\right)$ expressed by experimental data is shown in Eq. 5,

$$
Y_{2}=5.211-0.009 a-3.193 b+0.003 a b+0.925 b^{2}-0.148 b^{3}
$$

where $\mathrm{a}$ is the picking roller speed (rpm), and $\mathrm{b}$ is the speed of the harvester $(\mathrm{m} / \mathrm{s})$.

Figure 12 shows the contour map of the rotational speed and the working speed of the harvester in terms of the picking time. It can be concluded from Fig. 11 that under the conditions of a certain forward speed of the harvester, the picking time gradually decreases as the picking roller speed increases, which basically presents a linear relationship. When the rotational speed is stable at a certain level, the working speed of the harvester has a 
linear relationship with the picking time, i.e., the picking time decreases as the forward speed of the harvester increases. However, the response diagram and the partial return analysis show that the impact of the speed of the rotational speed on the picking time is greater than the impact of the operating speed of the harvester.

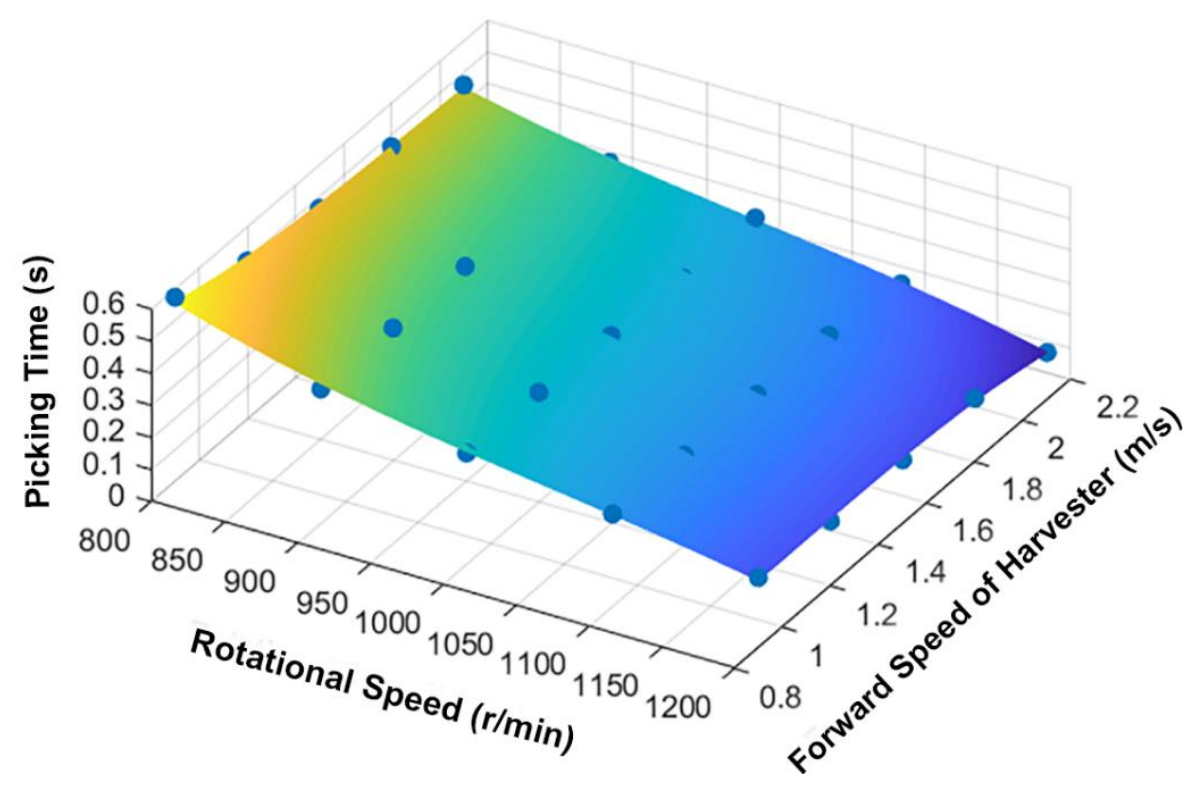

Fig. 12. Effect of the rotational speed and the forward speed of the harvester on the picking time

\section{CONCLUSIONS}

1. Based on the field measurements and statistics, the mechanical and physical parameters of a maize plant were obtained, and the maize plant modeling method for simulation was summarized. At the same time, based on the mechanical and physical parameters of the maize plant as well as the design experience, the key design parameters of the ear picking device were designed, and a solid model of the ear picking mechanism was established.

2. Based on virtual prototype technology and the force and motion analysis of a maize plant undergoing the ear picking process, the simulation method of the key components of a maize harvester was proposed. Based on the geometric structure parameters and material characteristic parameters of the primary working parts of the maize plant and ear picking mechanism, a solid model of the maize plant and picking device was imported into Hyper-Mesh software, and a finite element model of the interaction of the ear picking process was established.

3. Based on virtual prototype technology and the force and motion analysis of a maize plant undergoing the ear picking process, a method to evaluate the harvesting performance of a maize harvester with a longitudinal horizontal roll was proposed. Taking the contact force between the ears and the picking roller as the evaluation index, the influence of different dip angles between the picking roller and the ground on the picking performance was simulated. Taking the contact force between the ear and 
picking roller, as well as the picking time, as the evaluation indexes, the primary virtual simulation experiments were carried out to analyze the influence of two factors, i.e., the different rotational speed and the different harvester operating speeds, on the performance of the ear picking process. Meanwhile, a virtual orthogonal experiment was carried out to analyze two factors, i.e., the rotational speed and the forward speed of the harvester, and their influence on the picking performance was compared.

\section{ACKNOWLEDGMENTS}

The work was supported by the National key R\&D plan (2017YFD0700101).

\section{REFERENCES CITED}

Aguayo, M. M., Sarin, S. C., Cundiff, J. S., Comer, K., and Clark, T. (2017). "A maizestover harvest scheduling problem arising in cellulosic ethanol production," Biomass and Bioenergy 107, 102-112. DOI: 10.1016/j.biombioe.2017.09.013

Balastreire, L. A., Herum, F. L., and Blaisdell, J. L. (1982). "Fracture of maize endosperm in bending part II: Fracture analysis by fractography and optical microscopy," Transactions of the ASABE 25(4), 1062-1065. DOI: 10.13031/2013.33668

Brass, R. W., and Marley, S. J. (1973). "Low damage maize shelling cylinder," Transaction of the ASAE 5(2), 278-283. DOI: 10.13031/2013.37445

Cheng, X., Jia, X., Chen, M., and Li, Q. (2016). "Experiment and analysis on test device of maize ear picking by pulling stalk upwards," Transactions of the Chinese Society of Agricultural Engineering 32(22), 50-55.

Cook, D. E., Shinners, K. J., Weimer, P. J., and Muck, R. E. (2014). "High dry matter whole-plant maize as a biomass feedstock," Biomass and Bioenergy 64, 230-236. DOI: 10.1016/j.biombioe.2014.02.026

Cui, T., Fan, C., Zhang, D., Yang, L., Li, Y., and Zhao, H. (2019). "Analysis on research progress of mechanized maize harvesting technology," Transactions of The Chinese Society of Agricultural Machinery 50(12), 1-13.

Fan, G., Wang, H., Ji, J., Cao, W., Liu, H., Hao, J., Chen, D., Zhou, Z., and Wang S. (2002). "Analysis of influence factor on seed damage rate and loss rate during picking maize-cob," Transactions of the Chinese Society of Agricultural Engineering 18(4), 72-74.

Fu, Q., Fu, J., Chen, Z., and Ren, L. (2020). "Loss reduction mechanism and experiment on snapping of rigid-flexible coupling maize head," Transactions of the Chinese Society of Agricultural Machinery 51(4), 60-68.

Fu, Q., Fu, J., Chen, Z., Zhang, L., and Ren, L. (2019). "Influence of different maize ear position and orientation and water content on fracture mechanics of maize peduncle," Transactions of the Chinese Society of Agricultural Engineering 35(16), 60-69.

GB/T 21961 (2008). "Technical requirements for maize combine harvest," Standardization Administration of China, Beijing, China.

Geng, A., Yang, J., Zhang, J., Zhang, Z., Yang, Q., and Li, R. (2016). "Influence factor analysis of mechanical damage on maize ear picking," Transactions of the Chinese Society of Agricultural Engineering 32(22), 56-62. 
Hiregoudar, S., Udhaykumar, R., Ramappa, K. T., Shreshta, B., Meda, V., and Anantachar, M. (2011). “Artificial neural network for assessment of grain losses for paddy combine harvester a novel approach," in: Proceedings of the International Conference on Logic, Information, Control and Computation, 25-27 February, Gandhigram, India, pp. 221-231.

Liu, C., Huang, Y., Wang, Z., Tai, Y., Liu, L., Sun, C., and Liu, H. (2018). "Emergy analysis for transportation fuels produced from maize stover in China," Journal of Cleaner Production 174, 213-225. DOI: 10.1016/j.jclepro.2017.10.306

Martin, C. R., Converse, H. H., Czuchajowska, Z., Lai, F. S., and Pomeranz, Y. (1987). "Breakage susceptibility and hardness of maize kernels of various sizes and shapes," Applied Engineering in Agriculture 3(1), 104-113. DOI: 10.13031/2013.26655

Saini, J. K., Saini, R., and Tewari, L. (2015). "Lignocellulosic agriculture wastes as biomass feedstocks for second-generation bioethanol production: Concepts and recent developments," 3 Biotech 5(4), 337-353. DOI: 10.1007/s13205-014-0246-5

Srivastava, A. K., Herum, F. L., and Stevens, K. K. (1976). "Impact parameters related to physical damage to maize kernel," Transactions of the ASABE 19(6), 1147-1151. DOI: $10.13031 / 2013.36191$

Yang, L., Cui, T., Qu, Z., Li, K., Yin, X., Han, D., Yan, B., Zhao, D., and Zhang, D. (2016). "Development and application of mechanized maize harvesters," International Journal of Agricultural and Biological Engineering 9(3), 15-28. DOI: 10.3965/j.ijabe.20160903.2380

Zhang, Y., Gao, L., Liu, H., and Li, X. (2007). "Experimental study on maize kernel shear crash," Journal of Agricultural Mechanization Research 5, 136-138.

Zhao, X., Ma, Z., Sun, Y., and Wu, W. (1996). "Experimental study on mechanical properties of maize kernels," Journal of Jilin Agricultural University 26(1), 60-66.

Zhou, Q. (2010). "Experimental study on impact characteristics of corn ear," Agricultural Science and Technology \& Equipment 4, 34-35.

Article submitted: September 25, 2020; Peer review completed: December 19, 2020;

Revised version received and accepted: December 24, 2020; Published: January 6, 2021.

DOI: 10.15376/biores.16.1.1394-1410 